\title{
Liquid Biopsy
}

Amit Kumar Jain ${ }^{1}$ Guruprasad Bhat ${ }^{2}$ Vineet Govinda Gupta ${ }^{1}$ Hari Goyal ${ }^{1}$

${ }^{1}$ Department of Medical Oncology, Artemis Hospital, Gurugram, Haryana, India

${ }^{2}$ Department of Medical Oncology, Yenepoya Specialty Hospital, Mangalore, Karnataka, India

Ind J Med Paediatr Oncol 2021;42:77-79.

In the note below, we shall be discussing in brief about liquid biopsy in cancer under the following headings.

- Definition

- Need/advantages of liquid biopsy

- Types

- Methodology

- Limitations

- Uses in oncology

- Approved

- In research

- Future implication

- References

\section{Definition}

It is sampling and analysis of nonsolid biological tissue, primarily blood, to inform management. ${ }^{1}$

\section{Need of Liquid Biopsy}

There is a need of a technique that can complement or replace the traditional tissue biopsy overcoming the disadvantages and/or limitations associated with it.

Liquid biopsy:

- Offers the same simple, noninvasive, and faster than traditional biopsy.

- Allows assessment of intratumor heterogeneity, monitor tumor dynamics, and study tumor dormancy.

- Problems of tissue inadequacy are avoided as a few copies of mutant DNA are sufficient.

- Allows for serial evaluation (-Fig. 1). ${ }^{2}$

\section{Types}

Cancer cells shed intact cells as well as their cellular components (nucleic acids, exosomes) and with advancement in
Address for correspondence Amit Kumar Jain, DNB Medical Oncology Department of Medical Oncology, Artemis Hospital, Sector-51, Gurugram, 122001, Haryana, India (e-mail: 20akjain@gmail.com).

the laboratory techniques these can be isolated and analyzed (-Fig. 2). ${ }^{2}$

\section{Circulating Tumor Cells}

Cancer cells shed tumor cells into peripheral circulation mainly because of physical forces such as tumor growth, invasion of vessels rather than through epithelial mesenchymal transition that is an important mechanism in the development of metastasis., ${ }^{3,4}$

\section{Circulating Tumor DNA}

- Cancer cells undergo necrosis or apoptosis, releasing their DNA into the peripheral circulation.

- The circulating tumor DNA (ctDNA) has a short half-life and is present as small double-stranded DNA fragments of $\sim 150$ base pairs of nuclear or mitochondrial origin in body fluids.

- The ctDNA is stable when plasma is stored at $-80^{\circ} \mathrm{C} .^{2}$

\section{Exosomes}

- They are membrane-bound vesicles containing various proteins, RNA among other materials. They are released into a variety of body fluids.

- Exosomes derived from malignant cells have a higher concentration of proteins and a different RNA profile., ${ }^{3,5}$

\section{Tumor-Educated Platelets}

Several normal cells form a part of the tumor microenvironment. The interaction of these cells with tumor affects not only the gene expression in the tumor but also RNA expression in the platelets. Such platelets are called as tumor-educated platelets. ${ }^{6}$
DOI https://doi.org/ 10.1055/s-0041-1729434 ISSN 0971-5851
(C) 2021. Indian Society of Medical and Paediatric Oncology This is an open access article published by Thieme under the terms of the Creative Commons Attribution-NonDerivative-NonCommercial-License, permitting copying and reproduction so long as the original work is given appropriate credit. Contents may not be used for commercial purposes, or adapted, remixed, transformed or built upon. (https://creativecommons.org/licenses/by-nc-nd/4.0/).

Thieme Medical and Scientific Publishers Pvt. Ltd. A-12, 2nd Floor, Sector 2, Noida-201301 UP, India 


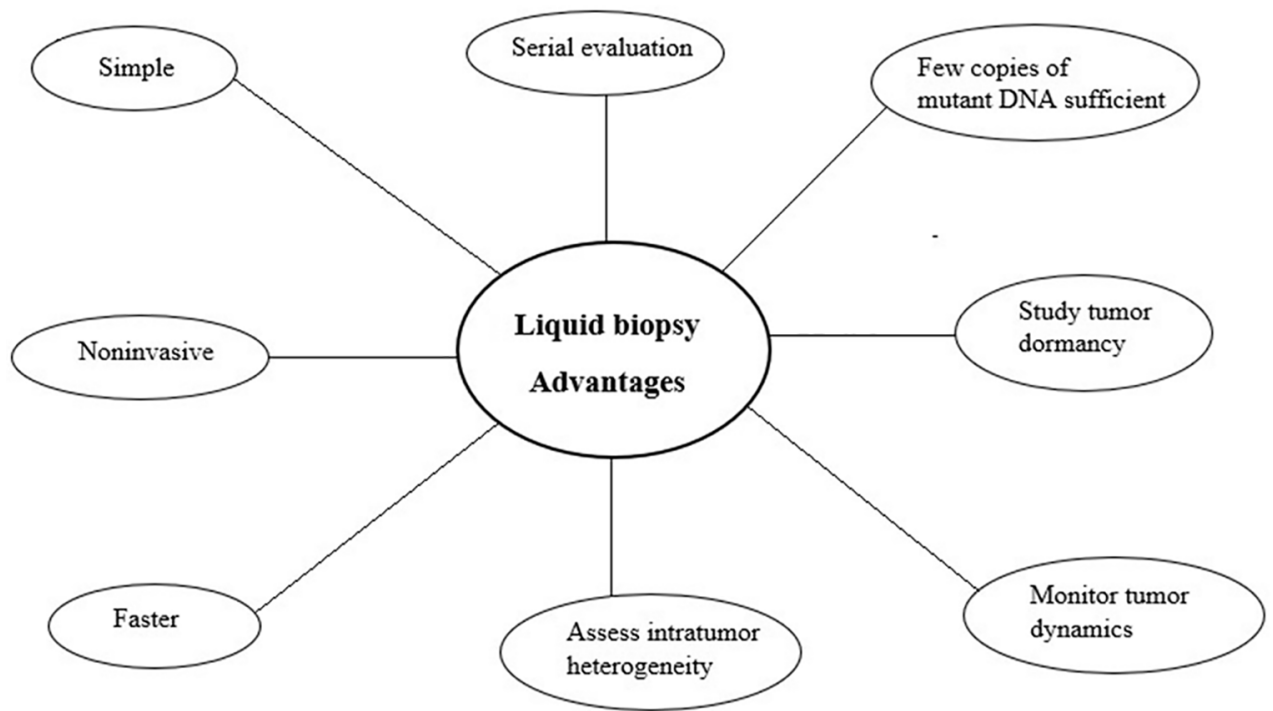

Fig. 1 Advantages of liquid biopsy.

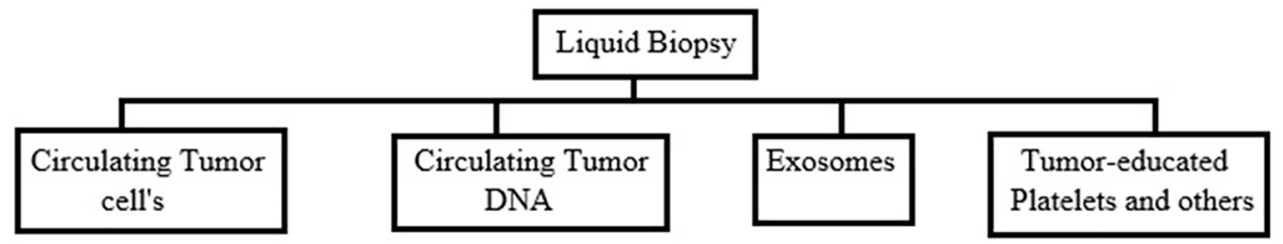

Fig. 2 Types of liquid biopsy.

\section{Methodology}

It involves

Sample collection

$\downarrow$

Isolation of circulating tumor cells (CTCs) and/or cellular components (nucleic acids, exosomes) by various enrichment techniques*

$\downarrow$

Isolated CTCs and/or ctDNA are analyzed further through wide variety of applications such as NGS, polymerase chain reaction, or fluorescence in situ hybridization to look for copy number, mutations, translocations, amplification, deletions, chromosomal abnormalities, RNA expression, fusion transcripts, protein expression, and phosphorylation and culture and data obtained from it is analyzed and interpreted.

*Several enrichment techniques used are positive selection using antibodies against epithelial markers, negative selection using anti-CD45 antibodies that will remove the white blood cells, and other mechanical methods like filtration are used., ${ }^{3,4}$

\section{Limitations}

- It cannot be used to determine histology (adenocarcinoma, squamous cell carcinoma), establish programmed death ligand 1 status.
- A negative test may not rule out true negativity example: Epidermal growth factor receptor (EGFR) negative on CTCs may still be positive on biopsy, nonshedders.

\section{Uses in Oncology}

\section{Approved}

- To detect actionable EGFR mutation in nonsmall cell lung cancer and RAS (KRAS and NRAS) and BRAF V600E muta-

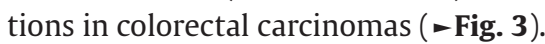

\section{In Research}

- Role in early detection of cancer is postulated. ${ }^{7}$

- Diagnosis (especially in difficult biopsy access site/ patient related problems for biopsy).

- Treatment selection (molecular profiling), prognostication (number of CTCs), and monitoring response (serial evaluation). ${ }^{8}$

- Risk of dissemination and detection of residual disease and recurrence.

- Identification of resistance mechanisms and monitoring clonal dynamics ( - Fig. 3 ).

\section{Future Implication}

Liquid biopsy is emerging as an important noninvasive technique that has both diagnostic and prognostic value. It is currently limited in routine use by the lack of convincing data 

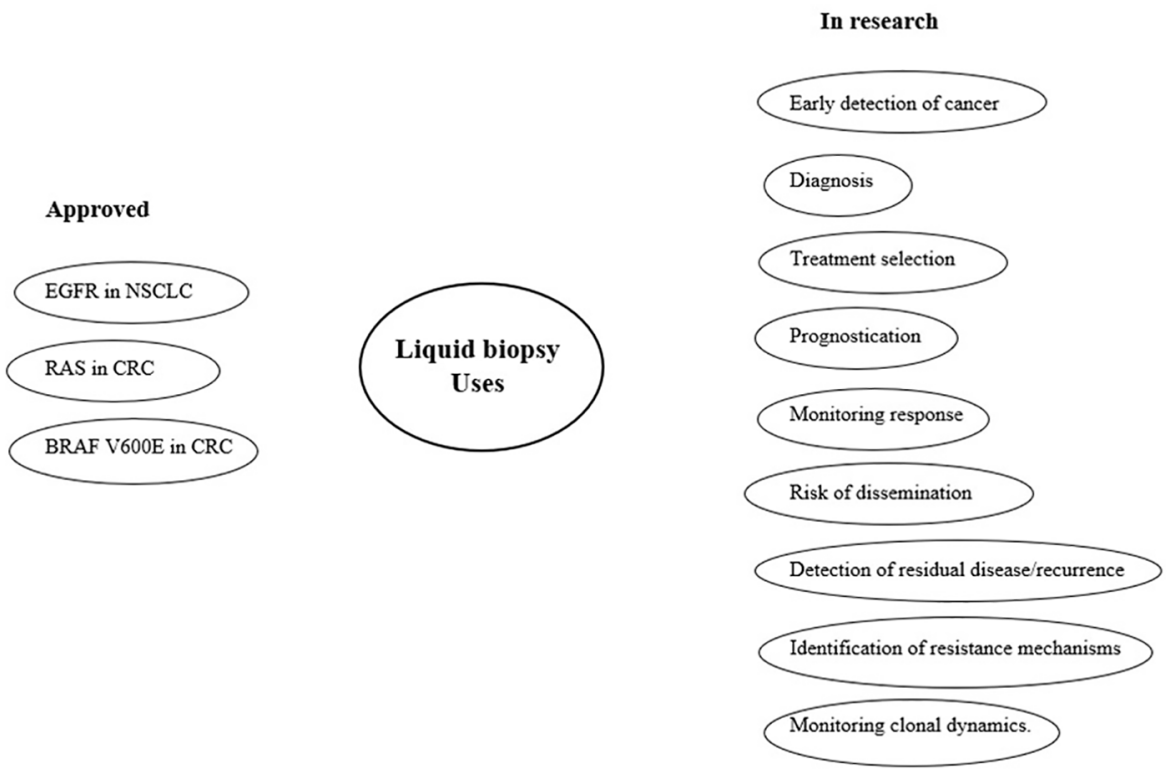

Fig. 3 Uses of liquid biopsy. CRC, colorectal cancer; EGFR, epidermal growth factor receptor; NSCLC, nonsmall cell lung cancer; RAS, .....; BRAF, .....

to replace the traditional tissue biopsy. However, with rapid advancements in the enrichment and isolation procedures, liquid biopsy represents an important prospect because of its many advantages.

\section{Financial Support and Sponsorship}

Nil.

\section{Conflicts of Interest}

There are no conflicts of interest.

\section{Acknowledgments}

We are grateful to Dr. Sujith Kumar, Consultant Medical Oncologist at Aster MIMS, Kannur, for his continuous guidance throughout the study.

\section{References}

1 Crowley E, Di Nicolantonio F, Loupakis F, Bardelli A. Liquid biopsy: monitoring cancer-genetics in the blood. Nat Rev Clin Oncol 2013;10(8):472-484
2 Diaz LA Jr, Bardelli A. Liquid biopsies: genotyping circulating tumor DNA. J Clin Oncol 2014;32(6):579-586

3 Rolfo C, Castiglia M, Hong D, et al. Liquid biopsies in lung cancer: the new ambrosia of researchers. Biochim Biophys Acta 2014;1846(2):539-546

4 Paterlini-Bréchot P. Circulating tumor cells: who is the killer? Cancer Microenviron 2014;7(3):161-176

5 Klevebring D, Neiman M, Sundling S, et al. Evaluation of exome sequencing to estimate tumor burden in plasma. PLoS One 2014;9(8):e104417

6 Joosse SA, Pantel K. Tumor-educated platelets as liquid biopsy in cancer patients. Cancer Cell 2015;28(5):552-554

7 Murray NP, Miranda R, Ruiz A, Droguett E. Diagnostic yield of primary circulating tumor cells in women suspected of breast cancer: the BEST (Breast Early Screening Test) study. Asian Pac J Cancer Prev 2015;16(5):1929-1934

8 Lv Q, Gong L, Zhang T, et al. Prognostic value of circulating tumor cells in metastatic breast cancer: a systemic review and meta-analysis. Clin Transl Oncol 2016;18(3):322-330 